\title{
MEDICINE
}

\section{IMPRESSION MATERIAL SELECTION AND SOFT TISSUE MANAGEMENT IN CONTEMPORARY FIXED PROSTHODONTICS}

\author{
Artak G. Heboyan, Assistant Professor, Department of Prosthodontics, Yerevan State Medical \\ University after M. Heratsi; Yerevan, Armenia; \\ Rafayel G. Muradyan, Prosthodontist, Private Practice, Yerevan, Armenia
}

DOI: https://doi.org/10.31435/rsglobal_wos/31052019/6499

\section{ARTICLE INFO}

Received: 26 March 2019

Accepted: 14 May 2019

Published: 31 May 2019

\section{KEYWORDS}

impression material, gingival retraction, polyether, tissue management, polyvinyl siloxanes.

\begin{abstract}
Whether impression is diagnostic or taken for provision of final restoration, its accuracy is crucial for the ultimate outcome. The objective of this review is to provide comprehensive, exhaustive and up-to-date information on impression materials and soft tissue procedures, which will facilitate the dentist's daily work in taking impressions to make various restorations. Taking precise impressions is rather challenging for even experienced dentists. It's rather difficult to achieve perfection, even despite the daily work with impression because of some issues, such as pulls, bubbles and missed margins. All the impression materials are different, each having their advantages and drawbacks. The impression taking technique is also very important, especially dealing with soft tissues and gingival retraction. The latter is important not only when working with different impression materials but taking digital impressions as well.
\end{abstract}

Citation: Artak G. Heboyan, Rafayel G. Muradyan. (2019) Impression Material Selection and Soft Tissue Management in Contemporary Fixed Prosthodontics. International Academy Journal Web of Scholar. 5(35). doi: 10.31435/rsglobal_wos/31052019/6499

Copyright: (C) 2019 Artak G. Heboyan, Rafayel G. Muradyan. This is an open-access article distributed under the terms of the Creative Commons Attribution License (CC BY). The use, distribution or reproduction in other forums is permitted, provided the original author(s) or licensor are credited and that the original publication in this journal is cited, in accordance with accepted academic practice. No use, distribution or reproduction is permitted which does not comply with these terms.

Introduction. Currently, the process of impression taking is regarded a combination of the scientific approach and creativity. The crucial element of the procedure is the optimal choice of both the material and method. The variety of impression materials, different in their physicochemical properties and indications for application are used in contemporary dentistry. Thus, the awareness of these is important to make a proper choice of impression material for various clinical cases [1]. Impression materials can be classified according to their composition, setting reaction and setting properties, but a commonly used system is based on the properties which occur after the material is set [2,3].

Properties of impression materials.

Viscosity.

Substances with low viscosity are characterized with high fluidity and vice versa. The viscosity of the substance increases with the percentage of filler. Thixotropy is the property of the substance to flow when under compression, and keep its shape when in static condition. Materials with low viscosity are also called corrective or spreading. Flowable, they allow the fine details to develop on the surface, but in practice they are not used on their own. Corrective mass is often used together with more thick substance, which supports a low-viscosity substance, providing hydraulic pressure.

Hydrophilicity.

Impression materials are characterized by hydrophilicity of different degree [4]. They can be hydrophilic, hydrophobic and hydro active. Hydrophilic substances are characterized by high affinity towards humidity (low wetting angle), good wettability and imprint the smallest details on the surface. Hydrophobic impression materials have low moisture affiliation (high wetting angle), characterized by 
poor wettability and small details imprint insufficiently [5,6]. Hydro active materials are common hydrophobic substances, whose hydrophilicity is enhanced due to the increase of the surfactant. As a result, surface high wettability and ability to imprint fine details are achieved.

\section{Setting time.}

Setting time of impression materials includes the whole period from kneading up to the complete hardening of the substance, when it's possible to remove the impression out of oral cavity without deformation. Working time is considered from kneading up to the moment, when manipulation of the material becomes impossible without deformation or the possibility of taking correct impression is missed. Impression material should be completely kneaded and placed in the oral cavity before the working time expires. Since the temperature of the environment has its impact on the setting time of all elastomeric impression materials, one of the ways to increase the working time is to cold the substance before kneading. Cooling impression materials by $2^{\circ} \mathrm{C}$ allows to increase the working time by 90 seconds, but applying auto mixing tips or devices, cooling of the material must be carried out with caution. Besides, cooling impression materials to the temperatures lower than $+18.3^{\circ} \mathrm{C}$ in different ways changes the flowability of the main substance and catalyst leading to the disturbance of their proportions. Factors affecting the working and setting time are humidity, bases and catalyst ratio as well as the method of substance kneading.

\section{Dimensional stability.}

Accurate imprint of intraoral structures on the impression depends on its dimensional stability. Dimensional distortion of impression can be conditioned by different causes, e.g. polymerization shrinkage, by-product release in the process of the setting of impression material, environmental humidity or absorption of oral fluid, as well as temperature change in the environment. Substances with high dimensional stability in practice are unchangeable within approximately 7 days, regardless the temperature change in the environment. Moreover, it should be possible to pour several precise casts from these materials.

Tear resistance and elastic recovery.

Impression material should be firm enough to be removed from oral cavity without damage (rupture). Substances with high tear energy provide the impression with high tear resistance. Elasticity allows the substance to resist tearing and come back to initial configuration, but every substance have elasticity limit which, when exceeded, makes reverse to primary shape impossible. The substance is preferable to tear rather than undergo permanent deformation at least within the finish line and inside the gingival sulcus. Permanent deformation depends on the stretching degree of sutured polymer, temperature and expression of applied loading.

Mentioned physical properties (tear resistance, elastic recovery) are very important in getting precise impression, taking it out of the oral cavity and separation from the cast. Impression material should have a high tear resistance and elastic recovery to make it possible to get several casts out of one impression. This property is considered as an advantage in the contemporary restorative dentistry [7].

\section{Impression Materials.}

\section{Alginates.}

Alginates are hydrophilic, i.e. moisture tolerant, so it can be used even in presence of moisture in the oral cavity, which is challenging with hydrophobic materials $[8,9]$. Dentists consider this substance to be quite accurate, easy to use and patient-friendly. Though, it requires accurate measurement and thorough kneading; the additional need for careful attention to set-time accuracy is less challenging with the triphasic materials which are now available, which change their color indicating the precise time for the tray to be set in the oral cavity and when to start timing the final set. The clinician must also take care to avoid pulls, which can cause distortion during removal. Due to its flexibility it is easily removed from the mouth, compared with other materials if they flow into undercuts. While using alginate impression, the cast should be poured within 10 minutes, otherwise it will be deformed [10]. To avoid distortion, the impression is kept in a humid environment. They can be wrapped in a wet paper towel or stored in a plastic box that is designed to contain humidity. Alginate materials are mostly used for study models, diagnostic work-ups on sets of mounted models, trial equilibration, or sending models to a laboratory to have a wax-up completed. They can be also applied to make a complete or partial removable dental prosthesis.

Alginate substitutes.

These substances have better mechanical properties than conventional alginate [11]. Alginate substitutes are of a lower cost than traditional PVS, but more expensive than alginate. Due to their hydrophobic properties, alginate substitutes require dry condition when used in the oral cavity, but not for storage or transport. Most of them require a custom tray and an auto mix delivery system, which provides a uniform consistency and precise setting times, facilitating the impression procedure. They 
are patient-friendly in terms of taste; manifest dimensional stability over the time, thus there is no need to rush to pour; improved detail reproduction; tear strength and can be poured multiple times with equal accuracy, enabling clinicians to have separate sets for office and laboratory [12]. Problems are usually associated with moisture on initial contact with the oral environment [13].

Polyvinyl siloxanes $(P V S)$.

PVS chemical reaction doesn't result in by-product occurrence, there is often a secondary reaction that can release hydrogen, which can lead to bubble formation in the gypsum cast. Thus, it is recommended to wait for 60 minutes before pouring a PVS impression. However, most of the modern PVS contain special additives, some platinum or palladium which prevent hydrogen release. PVS materials are considered one of the most preferable impression materials for making various restorations since they have excellent properties. There are PVS impression materials of different viscosity (from extra light body to putty) and the ones having the set times, intended for different clinical cases. Impressions made from this material produce great detail reproduction, manifest stability over the time and can be poured multiple times $[14,15]$ because of their high tear strength and high elastic recovery. Contact with latex rubber dams or latex gloves should be avoided, which may leave sulfur or sulfur compound that inhibits polymerization of the material, that's why taking impression by this material it is recommended to wear vinyl or nitryl gloves. Moreover, gingival retraction-soaked cords containing sulfur may also contribute to the inhibition. Methacrylate, acryl and petroleum jelly traces can also slow down PVS polymerization and decrease the ability of the substance to imprint small details on the surface. Thus, it is crucial to thoroughly clean prepared teeth and adjacent tissues before taking the final impression. Since PVS is hydrophobic, the denture bearing area should be kept as dry as possible [16]. PVS impressions can be disinfected by immersing in glutaraldehyde, phenol glutaraldehyde, natrium hypochlorite, complex phenols and iodophors. This type of sterilization is easy to carry on and it doesn't impact on the impression accuracy which maintains dimensional stability for 7 days.

Hydrophilic polyvinyl siloxane.

PVS is a hydrophobic substance, so proper moisture control is very important in order to obtain a high-quality impression. The newest PVS impression materials are considered hydrophilic and can be applied under the wet conditions. These materials contain intrinsic surfactants, which improve their wettability and facilitate the pouring process with gypsum materials. However, hydrophilic PVS seems to remain hydrophobic when it is still in the liquid, unpolymerized state and their wettability are compromised in the presence of moisture. As a result, their surface detail reproduction is inconsistent when moisture control is not maintained [17].

Polyether.

The setting reaction for these materials is via cationic polymerization, in which no by-product occurs. These substances are hydrophilic, which allows their application in moist environment. Their wettability makes the preparation of gypsum casts easier [18]: Polyether materials, when applies correctly, provide perfectly fine detail and accuracy in crown-and-bridge impressions [19]. The advantages are also the ability to do multiple pours and have a longer set time and long-term stability. Nevertheless, they are rigid and compared to PVS harder to remove from oral cavity especially when there are restorations or undercuts, however, contemporary polyether impression materials are slightly more flexible than the older products, which facilitates their removal from the oral cavity [20]. In addition, many patients object to their taste, though it was improved over the recent years. Due to its water absorption property, impression should not be immersed into water, as it will result in distortion. So, it is recommended to carry out ten-minute sterilization with glutaraldehyde afterwards it maintains its dimensional stability up to 7 days when under the dry conditions. These materials are available in low, medium, and high viscosities and can be used as a single-phase material or with a syringe-andtray technique. Dispensing is more often carried out via a motorized mixing unit, and custom impression tray is used to take an impression.

Vinyl siloxanether (vinyl polyether siloxane).

The new impression material combines the properties of polyether and PVS [21]: Vinyl siloxanether substances are produced in the form of a two-component system (base and catalyst). These kind of hybrid masses are of different viscosity (extremally high, high, medium and low) to obtain impressions using different methods. This material has been reported to combine the ease of removal of PVS with the hydrophilicity (wetting properties) of polyether [22], making it quite perspective substance for complicated cases, where moisture control is problematic e.g. because of narrow, deep gingival crevices. However, the literature on the accuracy of this new material is still scarce [23]. 


\section{Impression-making issues and instruments.}

Conditioned by the different properties and application peculiarities, impressions are taken by different techniques. Special attention should be paid to gingival retraction, especially when working with hydrophobic materials as the impression accuracy in this case is largely dependent on the moisture control. Thus, the quality and precision of the final impressions depends on a number of factors, such as the choice of material, patient's comfort, moisture control, hemostasis, method of gingival retraction and its duration, size and shape of the impression tray, the amount of impression material, method of substance kneading, fitting accuracy of provisional restorations and relevantly the condition of adjacent soft tissue, dealing with the gum while preparing the tooth and getting impression as well as the dentist's experience and skills.

At the stage of planning prosthodontic treatment, before the tooth preparation it is necessary to determine the distance between the marginal gum and underlying alveolar crest, in the area of vestibular and approximal surfaces of the teeth subject to restoration. The level of underlying alveolar crest can be characterized as normal, low or high. In case of the normal position of anterior teeth, this distance makes up about $3 \mathrm{~mm}$ on the vestibular side and $4 \mathrm{~mm}$ on the approximal side. It should be mentioned, that in presence of the adjacent teeth this ratio is observed in $85 \%$ of cases. Low position of the alveolar crest is characterized by higher rates and is observed in $13 \%$, while high position of the crest is observed in $2 \%$ of cases. Thus, the distance between the marginal gum and alveolar crest is smaller than the one mentioned above. In case of a normal position of the alveolar crest, initial bone-gum distance restores after the intervention in soft tissues and taking impression [24]. In the case of a high position of the alveolar crest, traumatic intervention and the finishing line shifting from the marginal gum to apical position results in too close location of the restoration edge towards the alveolar crest, i.e. impairment of biological width. The least stability is characterized by the low position of the alveolar crest and the thin biotype of the gum, as in these cases the recession probability of the soft tissues is high, while its severity is unforeseen. Thus, in presence of a high or low level of the alveolar crest prosthodontic treatment should be thoroughly planned. Before the preparation of the teeth, it's necessary to consider the expediency of altering the bone-gum ratio by means of surgical or/and prosthodontic methods. Moreover, these cases require great caution in every procedure. Optimal method of taking impression as well as the number and size of retraction cords should be chosen, taking into consideration the position of the alveolar crest and gum biotype. It is usually recommended to use one cord in case of a high or low position of the alveolar crest, and two cords in case of a norm.

Tissue management.

Tissue management is important to make a high-quality impression, based on which exquisite restorations such as crown-and-bridge, veneers, inlays, and onlays are made. Successful tissue management rests primarily on retraction, i.e. pushing tissue out of the way to make space for the impression material. This can be achieved by different methods, using retraction cords, retraction paste [25,26] and lasers [27]. The most commonly used technique is a combination of mechanical and chemical displacement, with the use of gingival displacement cords of various sizes and hemostatic agents such as aluminum chloride and ferric sulfate [28]. All retraction methods have their benefits and disadvantages. Thus, the choice of appropriate technique is conditioned by concrete clinical case. Therefore, the dentist should be armed with proper means to succeed in every clinical case.

Retraction cords.

The insertion of the gingival retraction cord into the gingival sulcus is quite an effective method of gum retraction. In case an intervention is performed correctly, the fluid release from the gingival sulcus can be safely blocked with a minimal risk of gingival recession. There are retracting cords which contain vasoconstrictors, and there are the ones which don't. To achieve the accuracy and quality of the impression, the minimum width of the gingival sulcus must be $0.2 \mathrm{~mm}$, and the minimum time to make the sulcus of this width is 4 minutes [29]. Retraction cords are normally placed on the entire perimeter of a prepared tooth, placing it at the top of the sulcus, so the entire diameter of the cord is visible and the clinician can ascertain that the flash of the light-body material will have the desired 1-mm depth and 1$\mathrm{mm}$ thickness. The tissue can partly cover the cord, in case it is placed too deep in gingival sulcus and it can prevent the light-body material from correctly recording a correct impression.

The cord is placed in the gingival sulcus and it mechanically stretches peripheric periodontal fibers. Its placement is often easily performed in case braided or knitted cords are used. However, braided cords of a big size should be avoided, since they tend to rotate and can appear too thick to be placed in gingival sulcus without causing trauma. In the areas where very narrow gingival sulcus hinders the placement of braided or twisted threads of a small size, woollike thread, which can be flattened, is preferable for the initial retraction of the tissue. More widening of the gingival sulcus can 
be obtained by means of cord saturated with chemicals, i.e. previously immersed in a styptic substance (e.g Hemodent). These substances contain aluminum or iron salts and cause self-limiting ischemia stimulating the sulcus contraction. Nevertheless, gingival sulcus closes very quickly (in less than 30 sec.) after the removal of the cord, so impression should be taken immediately. Besides, the absorption of the gingival fluid is controlled by the medicinal substances. Aluminum chloride $\left(\mathrm{AlCl}_{3}\right)$ and trivalent iron sulphate $\left[\mathrm{Fe}_{2}\left(\mathrm{SO}_{4}\right)_{3}\right]$ are preferable, since they cause minimal tissue damage.

The gum retraction can be performed by means of one or two cords. Initially, they are placed on a medial side, then for the stability it is lightly placed in distal. Thereafter, starting with medial side, the cord is placed on a lingual side, moving towards the distal. The instrument should be placed at an angel to the tooth to immediately insert the cord into the gingival sulcus. It should also be located at a small angle over the already-placed cord (medial), otherwise the thread will come out of the gingival sulcus. In the process of cord insertion, there might be second instrument needed - one sustains the cord, the other continues to perform retraction. If the cord anyway goes out, it should be kept by the instrument longer or a thinner cord should be used. The excess cord on the medial side is cut as close to interdental papilla as possible. Afterwards, the cord is place on the vestibular side. The distal end of the cord should overcover the medial one. The rest of cord is to be removed. In case the two cords are used, the first (thin) cord is equalized and placed in a way that its ends not overlap each other. The second one is placed atop, getting side displacement of the tissue. The latter is removed right before getting impression, leaving the first cord in its place to reduce moisturizing. To succeed in this method, there should be about $1 \mathrm{~mm}$ non-prepared tooth area between the first cord and preparation margin. When applying this method, excessive pressure on the tissue should not be applied, as this may cause damage to the epithelial tissue.

\section{Retraction paste.}

This technique includes syringing a synthetic polymer material into the non-retracted gingival sulcus; in contact with crevicular fluid this substance expands and provides desired displacement with minimal time and trauma. Conventional and cordless gingival displacement techniques show the same effectiveness and both have minimal influence on periodontal tissue [30,31]. However, the recent researches have shown that cordless techniques were less stressful for the patients, and also produced lower post treatment levels of proinflammatory cytokines in the crevicular fluid compared with conventional techniques. Cordless techniques have also been reported to be less time consuming and easier to use compared with displacement cords. One study reported that cordless techniques cause 10 times less pressure on gingival tissue, compared with conventional techniques, which include the application of displacement cords [32]. This significantly lower pressure indicates that cordless techniques potentially cause less trauma to the periodontal tissues; however, it could also signify a reduced efficacy at achieving adequate gingival displacement, which clinically translates to a less successful impression. The highest pressures were generated with the use of Expasyl (Acteon, Mt Laurel, NJ), a paste-like material used for gingival retraction. In a study comparing the effects of conventional and cordless gingival displacement techniques on the periodontal health of healthy subjects, use of Expasyl resulted in slower healing and significant increase of the gingival index compared with a different PVS expanding material (Magic Foam Cord, Colte ne/Whaledent, Cuyahoga Falls, $\mathrm{OH}$ ) or with conventional displacement cords [33].

Lasers.

Lasers usually cut or, as termed in laser technology, trough. Through laser, the dentist literally thinning/removing the free gingival margin tissue, creating a $1 \mathrm{~mm}$ space for impression material. Care should be taken not to shorten the tissue unless a gingivectomy is intended. With most lasers, if the settings are correct, the coagulant effect of the laser energy allows the clinician to control the sulcular fluid and hemorrhage [34].

Unhealthy gingival tissue.

When the gingival tissue is healthy, retraction is usually carried out immediately after the tooth preparation. However, in case of inflamed gingival tissue, periodontitis, over-contoured old restorations and plaque, getting impression should be postponed until the situation is managed [35], as the teeth preparation and taking impression in presence of the gum inflammation, baring the edges of the construction, increases further risk of soft tissue recession. Correction of the condition involves the preparation of a provisional restorations, rinsing oral cavity with antiseptic solutions, using an interdental brush or a rubber tip stimulator. Retraction paste together with retraction cords is recommended if getting impression is needed in these undesirable conditions.

Disinfection of conventional impressions.

Dental impressions get in contact with the blood and/or oral fluid [36]; thus, dental office must follow the disinfection protocol to decrease the risk of cross-contamination [37]. In order to increase 
efficiency, the disinfection should be carried out immediately after removing the impression out of the mouth. A number of researches elucidate the influence of the disinfection process on the surface properties and dimensional stability of dental impression materials [38-41]. These studies reveal that disinfection doesn't have significant clinical impact on impression quality and/or accuracy. The process of disinfection consists of two stages. The first stage includes rinsing the impression with tap water immediately after removing it from the mouth. This procedure considerably reduces the number of blood-borne pathogens that can be transferred to the stone casts. The second stage consists of spraying the impression with disinfecting substance or immersing it in a chemical solution for a specified amount of time. Special caution should be taken while disinfecting water-based substances or polyether, since extended immersion times (>30 minutes) can have a negative influence on impression quality [42]. The impact of disinfecting substance on the hydrophilicity of PVS has been studied, which is attributed to the removal of added surfactants from the material, which harms the impression surface and cast quality [43]. One of the researches [44] revealed that chlorine-based disinfecting agents are less effective in removing nonionic surfactants from PVS impression materials compared with quaternary ammonium-based agents. The investigators recommended using a wetting agent to counteract the loss of surfactants and reduce the hydrophobicity of PVS before pouring the impression. In general, prolonged disinfection times should be avoided because of their adverse effects on contact angle and material wettability.

\section{Considerations for digital impressions.}

Though digital impressions don't require the use of impression materials, tissue management and retraction are still as important as ever. Using digital impressions effectively requires a familiarity with the hardware and software involved. Issues like file storage and file transfer to the laboratory become technology issues each practice has to address.

Currently, among the range of available digital systems, one difference to consider is the size and feel of the camera and dealing with camera is very important to get an accurate image. Installation of the camera can be rather challenging in patients with small mouth or limited mouth opening ability. Similarly, multiple tipped teeth will require skillful movement of the camera to accurately capture all of the tooth surfaces and line angles. The size of digital impression system in a multi-operatory office, the ease of moving it from room to room should be taken into account. A hybrid technique available today is to use a box scanner and digitize a traditional impression.

Conclusions. The quality of the obtained impression has a direct impact on the quality of restorations we make and the daily dental services we provide. Being a composing stage of a work, impressions are taken for different purposes, such as diagnostics, restorative, orthodontics, or even advanced oral surgery procedures. Thus, in order to succeed in a daily work it is important to be aware of advantages and drawbacks of the impression materials and impression getting technology peculiarities. Moreover, positive outcome of getting impression can be achieved only in case if soft tissues are perfectly healthy, tooth preparation and gum retraction have been properly performed.

\section{REFERENCES}

1. Perry R. Dental impression materials. J Vet Dent 2013;30:116-24

2. Lu H, Nguyen B, Powers JM. Mechanical properties of 3 hydrophilic addition silicone and polyether elastomeric impression materials. J Prosthet Dent 2004;92(2):151-154

3. Walker MP, Petrie CS, Haj-Ali R, Spencer P et al. Moisture effect on polyether and polyvinylsiloxane dimetional accuracy and detail reproduction. J Prosthodont 2005;14(3):158-163

4. Pitel ML. Successful impression taking. First time. Everytime. $1^{\text {st }}$ ed. Armonk, NY: Heraues Kulzer; 2005.

5. Lee EA. Impression material selection in contemporary fixed prosthodontics: technique, rationale, and indications. Compend Contin Educ Dent 2005;26(11):780-789

6. Jonson GH, Lepe X, Aw TC. The effect of surface moisture on detail reproduction of elastomeric impressions. J Prosthet Dent 2003,90(4):354-364

7. Lee EA. Impression-taking considerations for predictable indirect restorations. Pract Proced Aesthet Dent 2003;15(6):454-457

8. Rubel BS. Impression materials: a comparative review of impression materials most commonly used in restorative dentistry. Dent Clin North Am 2007;51(3):629-42, vi.

9. Kulkarni MM, Thombare RU. Dimensional changes of alginate dental impression materials - an in vitro study. J Clin Diagn Res. 2015;9(8):ZC98-ZC102. doi: 10.7860/JCDR/2015/13627.6407. Epub 2015 Aug 1.

10. Donovan TE, Chee WW. A review of contemporary impression materials and techniques. Dent Clin North Am 2004;48(2):vi-vii, 445-470.

11. Baxter R, Lawson N, Cakir D, et al. Evaluation of outgassing, tear strength, and detail reproduction in alginate substitute materials. Oper Dent 2012;37(5):540-7. 
12. Nassar U, Hussein B, Oko A, et al. Dimensional accuracy of 2 irreversible hydrocolloid alternative impression materials with immediate and delayed pouring. J Can Dent Assoc 2012;78(78):c2.

13. Burgess JO. Impression material basics. Inside Dentistry. 2005;1(1).

14. Shaba OP, Adegbulugbe IC, Oderinu OH. Dimensional stability of alginate impression material over a four-hour time frame. Nig Q J Hosp Med. 2007;17(1):1-4.

15. Nassar U, Oko A, Adeeb S, et al. An in vitro study on the dimensional stability of a vinyl polyether silicone impression material over a prolonged storage period. J Prosthet Dent. 2013;109(3):172-178. doi: 10.1016/ S0022-3913(13)60038-4.

16. Perry R. Using polyvinyl impressions for study models: a case report. Dent Today. 2004; 23:106-107.

17. Petrie CS, Walker MP, O'Mahony AM, et al. Dimensional accuracy and surface detail reproduction of two hydrophilic vinyl polysiloxane impression materials tested under dry, moist, and wet conditions. J Prosthet Dent 2003; 90(4):365-72.

18. Sakaguchi RL, Powers JM. Craig's restorative dental materials. Philadelphia (PA): Elsevier Health Sciences; 2012.

19. Nagrath R, Lahori M, Agrawal M. A comparative evaluation of dimensional accuracy and surface detail reproduction of four hydrophilic vinyl polysiloxane impression materials tested under dry, moist, and wet conditions - an in vitro study. J Indian Prosthodont Soc. 2014;14(Suppl 1):59-66. doi: 10.1007/s13191-014-0365-z. Epub 2014 May 11.

20. Powers J, Wataha J. Dental materials foundations and applications. 11th edition.St. Louis (MO): Elsevier; 2017.

21. Enkling N, Bayer S, Jo hren P, et al. Vinyl siloxanether: a new impression material. clinical study of implant impressions with vinyl siloxanether versus polyether materials. Clin Implant Dent Relat Res 2012;14(1):144-51.

22. Walker MP, Alderman N, Petrie CS, et al. Correlation of impression removal force with elastomeric impression material rigidity and hardness. J Prosthodont 2013;22(5):362-6.

23. Stober T, Johnson GH, Schmitter M. Accuracy of the newly formulated vinyl siloxanether elastomeric impression material. J Prosthet Dent 2010;103(4):228-39.

24. Vakay RT, Kois JC. Universal paradigms for predictable final impressions. Compend Contin Educ Dent 2005;26(3):199-206

25. Donovan TE, Chee WW. Current concepts in gingival displacement. Dent ClinNorth Am 2004;48(2):433-44.

26. Baba NZ, Goodacre CJ, Jekki R, et al. Gingival displacement for impression making in fixed prosthodontics: contemporary principles, materials, and techniques. Dent Clin North Am 2014;58(1):45-68.

27. Scott A. Use of an erbium laser in lieu of retraction cord: a modern technique. Gen Dent 2005;53(2):116-9.

28. Ahmed SN, Donovan TE. Gingival displacement: survey results of dentists' practice procedures. J Prosthet Dent 2015; 114(1):81-5. e1-2.

29. Terry DA. The impression process: part 3-metal selection. Pract Proced Aesthet Dent 2006;18(9):576-578

30. Sarmento H, Leite F, Dantas R, et al. A double-blind randomised clinical trial of two techniques for gingival displacement. J Oral Rehabil 2014;41(4):306-13.

31. Acar Ö, Erkut S, Özc elik TB, et al. A clinical comparison of cordless and conventional displacement systems regarding clinical performance and impression quality. J Prosthet Dent 2014;111(5):388-94.

32. Bennani V, Inger M, Aarts JM. Comparison of pressure generated by cordless gingival displacement materials. J Prosthet Dent 2014;112(2):163-7.

33. Al Hamad KQ, Azar WZ, Alwaeli HA, et al. A clinical study on the effects of cordless and conventional retraction techniques on the gingival and periodontal health. J Clin Periodontol 2008;35(12):1053-8.

34. Stuffken M, Vahidi F. Preimpression troughing with the diode laser: a preliminary study. J Prosthet Dent. 2015 Dec 23. pii: S0022-3913(15)00611-3. doi: 10.1016/j. prosdent.2015.10.008. Epub ahead of print.

35. Ahmed SN, Donovan TE, Rau CT. Accurate elastomeric impressions: the importance of effective soft tissue management. J Esthet Restor Dent. 2016 Jan 5. doi: 10.1111/jerd.12191. Epub ahead of print.

36. Choi Y-R, Kim K-N, Kim K-M. The disinfection of impression materials by using microwave irradiation and hydrogen peroxide. J Prosthet Dent 2014;112(4):981-7.

37. Estafanous EW, Palenik CJ, Platt JA. Disinfection of bacterially contaminated hydrophilic PVS impression materials. J Prosthodont 2012;21(1):16-21.

38. Bock JJ, Werner Fuhrmann RA, Setz J. The influence of different disinfectants on primary impression materials. Quintessence Int 2008; 39(3): e93-8.

39. Demajo JK, Cassar V, Farrugia C, et al. Effectiveness of disinfectants on antimicrobial and physical properties of dental impression materials. Int J Prosthodont 2015;29(1):63-7.

40. Walker MP, Rondeau M, Petrie C, et al. Surface quality and long-term dimensional stability of current elastomeric impression materials after disinfection. J Prosthodont 2007;16(5):343-51.

41. Yilmaz H, Aydin C, Gul B, et al. Effect of disinfection on the dimensional stability of polyether impression materials. J Prosthodont 2007;16(6):473-9.

42. Kotsiomiti E, Tzialla A, Hatjivasiliou K. Accuracy and stability of impression materials subjected to chemical disinfection-a literature review. J Oral Rehabil 2008;35(4):291-9.

43. Blalock JS, Cooper JR, Rueggeberg FA. The effect of chlorine based disinfectant on wettability of a vinyl polysiloxane impression material. J Prosthet Dent 2010;104(5):333-41.

44. Kang YS, Rueggeberg F, Ramos V. Effects of chlorine-based and quaternary ammonium-based disinfectants on the wettability of a polyvinyl siloxane impression material. J Prosthet Dent 2017;117(2):266-70. 